\title{
DEAFSPACE DESIGN CONCEPT AS A MEANS OF SOCIALIZING STUDENTS WITH HEARING IMPAIRMENTS
}

\author{
Katrichenko K. O.
}

\section{INTRODUCTION}

As of the beginning of the XXI century, drastic changes in approaches to the New Educational Program require urgent identification of ways to develop them. The primary goal of which was to intensify inclusive processes for students with disabilities. In this regard, there is an urgent need to systematize the basic criteria of the concept of DeafSpace Design with the confirmation of the results in the visual materials of the best examples of design of educational spaces of secondary schools. The relevance of the research topic is due to the noticeable trend of changing ways of solving the problems of the New Educational Program.

\section{DeafSpace design philosophy, basic criteria of its implementation}

The design of the subject-space environment of a school with hearing impairments requires significant changes due to the need for such children to use sign language and communicate in a more open space. For them, sight and touch are the main means of facilitating spatial awareness and orientation in the school space.

Analysis of the material showed that the problems of people with hearing impairments began to be addressed in America after 1818, when the first school for deaf children appeared. The next successful step was the formation in 1864 of Gallade College (now Gallaude University). At the end of the twentieth century, the college staff formed the so-called philosophy of "lovers of the deaf" for use in the education system, which was later called total communication. The main criteria of the above philosophy was the use of American sign language and lip reading. Today, these steps have been transformed into the current system of inclusive education, which takes into account the problems of children with hearing impairments. Thus, project developments to improve the space of the school in which children with hearing impairments are educated, need to define and systematize the main characteristics.

If earlier the quality of life of people with hearing impairments was almost ignored by design specialists, today the problems have become very acute. It should be noted that the issue of inclusiveness for this category of people became widely used almost 10 years ago. In today's world, a set of architectural issues that need to be addressed in practice is defined as the 
concept of DeafSpace Design. According to experts (hearing-impaired designer, researcher Robert Sirvage, Hansel Baumann with a group of students), the main motto of this concept is to improve the ways and means of mastering the space around you. To implement the DeafSpace Design concept, architects Hansel and Dirksen Bauman (USA) took time to analyze the current situation in the design organization of the architectural space and form key principles for creating a creative environment (Fig. 1).

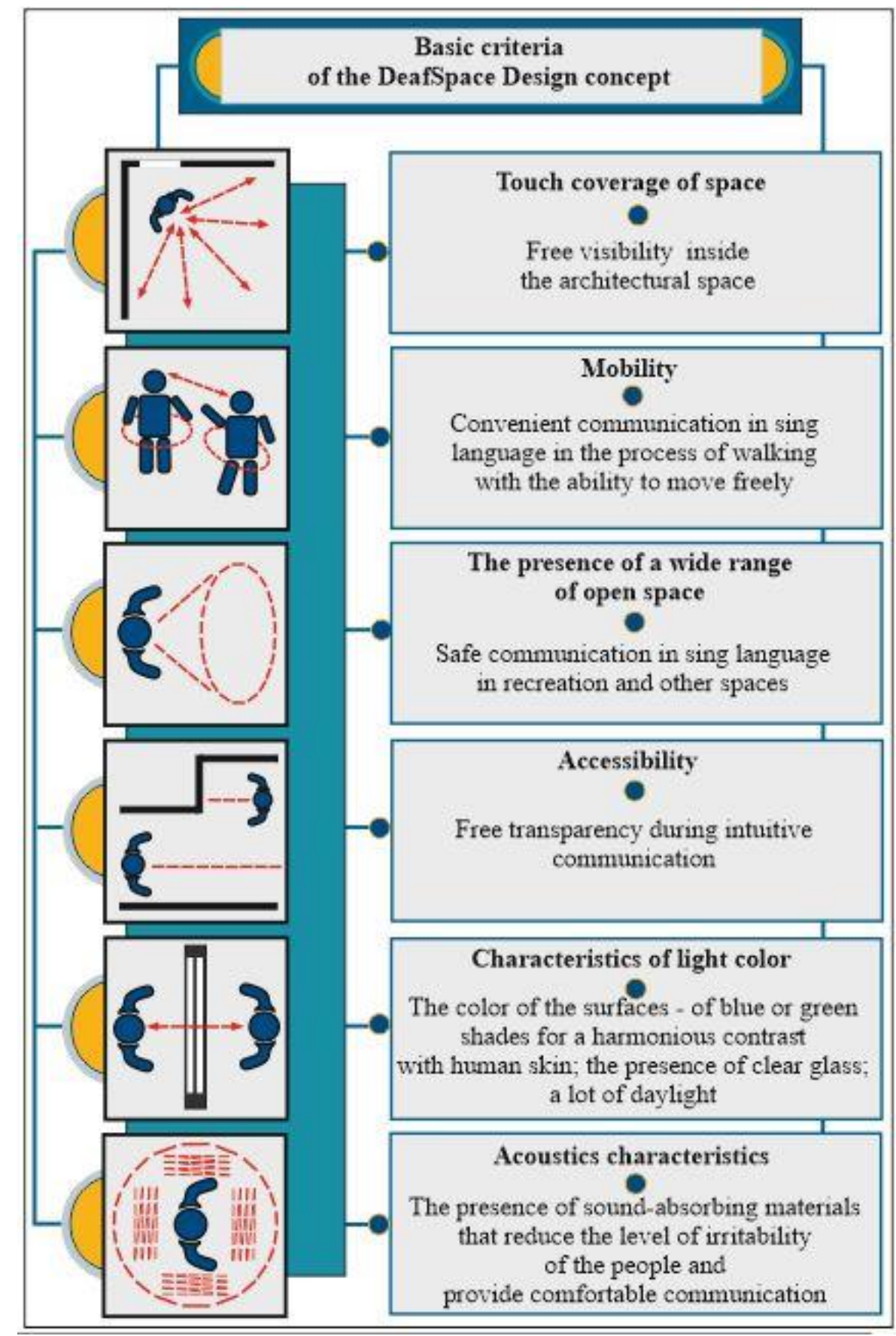

Fig. 1. Basic criteria of the DeafSpace Design concept 
The architectural task includes designing objects not only for people with hearing impairments, but also for all citizens without exception. Thanks to the human-centered approach, specialists managed to systematize the basic principles of visual communication paths in the architectural space, i.e. to identify the dominant code of communication, which simultaneously combines visual and kinesthetic properties that require a wide range of vision and space for people with hearing impairments. This approach in the era of global changes in the design of the subject-spatial environment is promising due to the fact that it focuses on the perception and emotions of each person and helps to interact on a physical level with the environment. So, let's look at the basic criteria of the DeafSpace Design concept proposed by the Bauman brothers-architects:

1) the presence of a wide range of open space and distance: the processes of sign language communication require free movement not only of the face but also of the whole body. This factor means addressing the balance between a person's desire for openness and his sense of security in times of communication. The result of solving safety aspects is: 1) the presence of radius corners in the room; 2) comfortable ergonomic design of furniture and equipment; 3 ) the formation of niches or small recreation for the convenience of conversations;

2) sensory access: an important factor here is the free visibility within the architectural space (corridors, the general perspective of the architectural space), which provides: 1) transparency; 2) the presence of surfaces with no glare;

3) mobility and accessibility, which contribute to visual transparency and intuitive navigation: solving issues of convenient communication in the process of walking with the ability to move freely and see your interlocutor, namely: 1) the presence of extended stairs; 2) the presence of wide automatic doors; 3 ) the presence of slopes and rises with a small angle of inclination; 4) rounded turns (to avoid collisions with other people); 5) combinatorial design organization of furniture in space - on the basis of radial forms (to create a circle of communication and support communication, common for people with hearing impairments) and with the possibility of reorganization in the process of communication; 6) marking on vertical surfaces (walls, enclosing structures); 7) the use of transparent glass structures in the design of premises;

4) color features: matte surfaces of blue and green shades, which harmoniously contrast with the shades of human skin, are desirable for the solution of the architectural space. The result of such a proposal in the design of architectural space is a comfortable perception of the gesturing interlocutor, whose skin color is manifested against the background of the proposed color scheme in the room; 
5) features of light: lighting is proposed to be soft, diffused, without excessive illumination and brightness, preferably without differences in illumination. Particular attention should be paid to maximizing the use of large amounts of natural light;

6) features of acoustics, which should be without distracting and irritating sounds in the formation of the interiors of secondary schools (Fig. 1) ${ }^{1}$.

All the above criteria contribute to improving the quality of life and communication of people with hearing impairments.

\section{Principles and techniques of design organization of educational space}

Considering the above characteristics, we should pay attention to the most successful examples of design organization of secondary schools with their subsequent systematization. Thus, in the context of the New Educational Program, the issues of planning and design organization of the classroom space with the provision of visual and acoustic equivalence become important. The first aspect - the presence of a wide range of open space and distance considers the possibilities of design organization of educational space, in which the placement of jobs meets the principle of openness. The compositional structure of the arrangement of furniture for students with hearing impairments is aimed at meeting the necessary criteria, namely: 1) preservation of hearing; 2) the development of its residual characteristics; 3 ) formation of the quality of verbal language on the basis of current analyzers (tactile-vibrational and visual). All the above criteria are met by the static organization of space based on the reception of mirror symmetry or the reception of visual equivalence. According to the research material, in order to avoid collisions of one student with hearing impairments with another during communication, they must follow the following necessary rules, namely (Fig. 2):

- walking near the columns in the school space - move next to each other;

- to support the conversation - keep sighting lines within the architectural space;

- to reduce the feeling of deep anxiety - helps the absence of unnecessary architectural structures, behind which you can not hear the footsteps of another child.

A striking example of the above is the design of a high school for children with hearing impairments in Tennessee, USA (Fig. 3). The main criteria for the formation of the design of this school was to take into account the main characteristics that correspond to the concept of DeafSpace Design, namely:

- planning solution of space ensures the preservation of aiming lines within the architectural space, which allows all students without exception to move safely in the internal subject-spatial environment;

\footnotetext{
${ }^{1}$ Bauman H. Deaf Diverse Design Guide. Identifying the Principles of Deaf Space. 2008, November 9. URL: http://www.dangermondarchitects.com/blog/.
} 


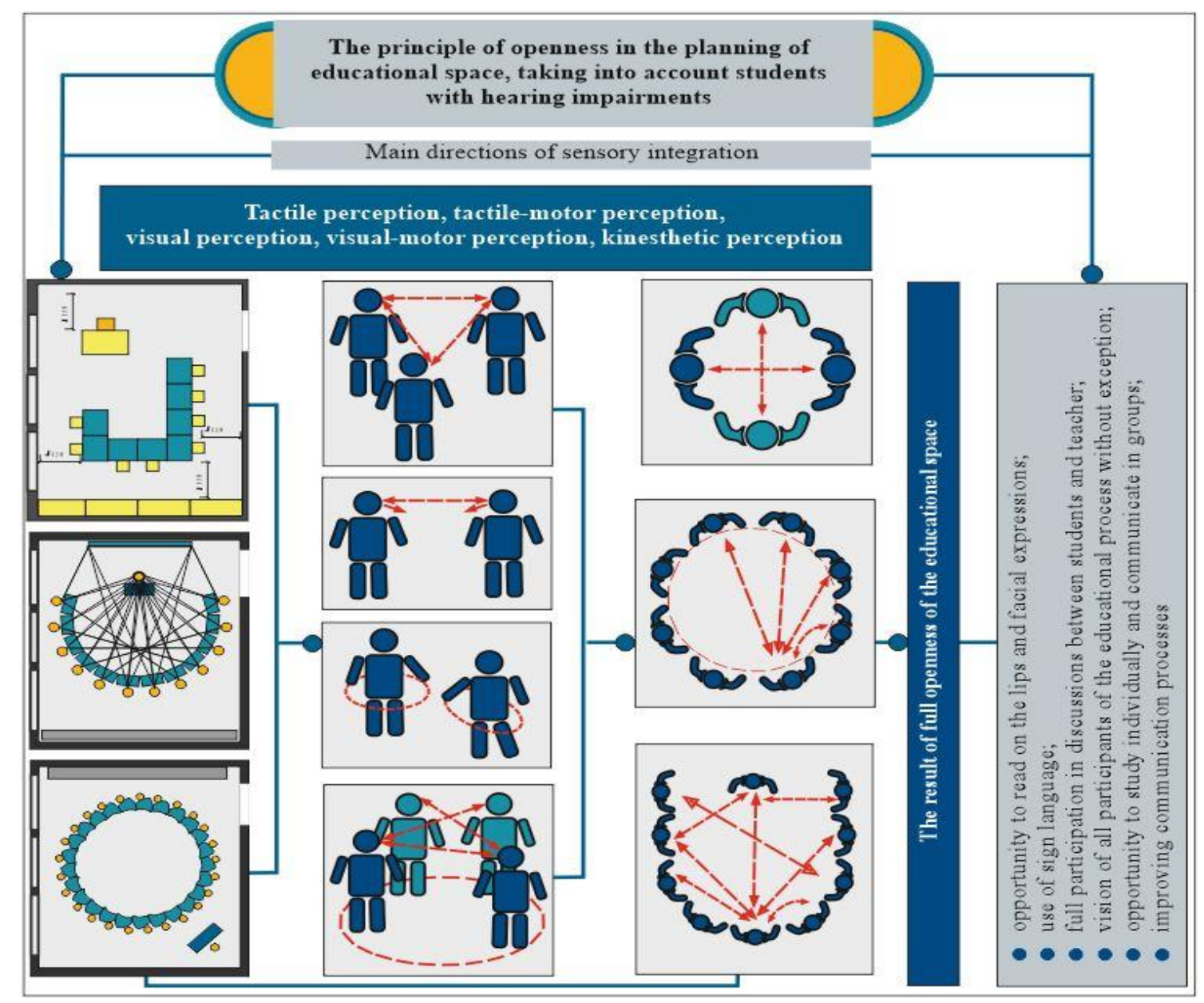

Fig. 2. Principle of openness in the planning of educational space, taking into account students with hearing impairments

- the presence of a large amount of daylight makes the space of classrooms aesthetically expressive and comfortable for classes;

- a minimum of flashes in the classroom space creates a positive psychoemotional atmosphere;

- the use of indirect lighting of the ceiling helps: 1) even distribution of light in the classroom; 2) reduction of sparkles on the surfaces of walls, ceilings; 3) no shadowing; 4) and also illusory increases the volume of the room.

The analysis of the research material showed that for students with visual impairments the most important task in the design of the study space is the location of workplaces in a U-shape. Visual openness in this arrangement of furniture is achieved in full, which promotes full communication between the teacher and, if necessary, with each student in the class. The result of the above transformations is a successful communicative environment with a positive psycho-emotional state of all participants in the learning process. It should be noted that the chosen color scheme of the school interiors, common monochrome for all rooms, helps to reveal the significance of the functional area, which is the main one in the interior. Yes, the design of the school lobby, the first interior in which students get, is decided in white and gray 
shades. However, the main areas: security area, administrator, recreation area - highlighted by contrasting colors on the floor and three-dimensional white elements on the ceiling.

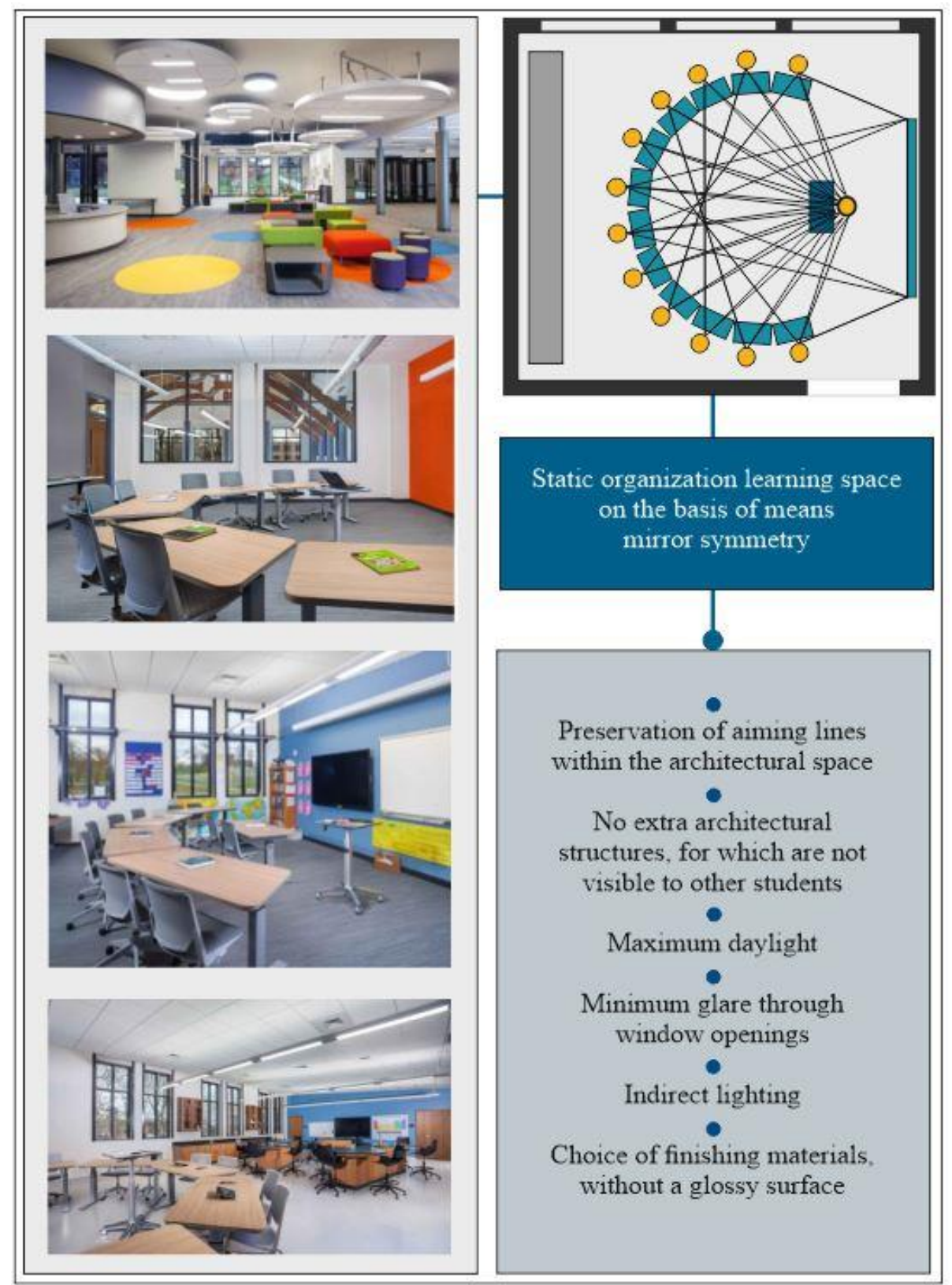

Fig. 3. Static organization of the classroom. School for Deaf Children, Tennessee, USA (URL: http://www.lewisgroup.net/projects/view/ tennessee_school_for_the_deaf)

In the design of classrooms, the main color is white, but due to the presence of a contrasting accent color in the area of the board, students' attention is focused on learning the material. The general harmonious composition of the school premises, based on the arrangement of architectural and decorative 
elements, balanced color and tonal relations and successful compositional solution of workplaces based on the reception of mirror symmetry, reflects a modern approach to the processes of aesthetic education of students (Fig. 3).

The following example of Frank Barnes Secondary School (London) for students with hearing impairments was developed by architect David Morley (Fig. 4). The main concept is based on the idea of unity of school space for ordinary students and children with hearing impairments who are in it for a long time. According to the research material, the ease of perception of interiors is achieved due to the balance of neutral colors of all rooms with the addition of contrasting accents to identify functional areas, enhance the perception of workplace location and schedule students. In addition, to create the design of the educational space, the architect solved the following specific tasks, namely: 1) proposed structures and materials that have soundabsorbing characteristics. The result of this task was to reduce the noise level during the direct communication of students; 2) the solution of natural light through the use of large windows and upper window openings on the ceiling; 3) the use of environmentally friendly materials, such as noraplan (noraplan ${ }^{\circledR}$ ), which have high sanitary and hygienic characteristics, do not require washing the floor with chemicals, have high-quality sound absorption when walking, excellent slip resistance, etc. To maintain visual openness, all doors (exterior and interior) are offered using clear glass, so students with hearing impairments have the opportunity to see another person. The final criterion for recognizing the quality of design of the Frank Barnes School was the award of the world's most famous quality mark, the Angel. Created in 1978 at the initiative of the German Federal Minister for Ecology and Lands, the quality mark indicates that in this case the architect and his professional team offered the best samples of environmentally friendly finishing materials with low emissions and safe carcinogens. According to the research material, the use of such materials positively contributes to the health of students and school staff.

The main conceptual idea: creating the unity of the school space for regular students and students with hearing impairments:

1) absence of superfluous architectural designs on which it is not visible other students;

2) preservation of aiming lines within the architectural space;

3) choice of finishing materials that do not have a glossy surface;

4) maximum daylight (presence of large windows, top natural light);

5) the general color scale of rooms - neutral;

6) reception of color contrast in the decision of the main functional zones;

$7)$ receiving color contrast in workplace design. 


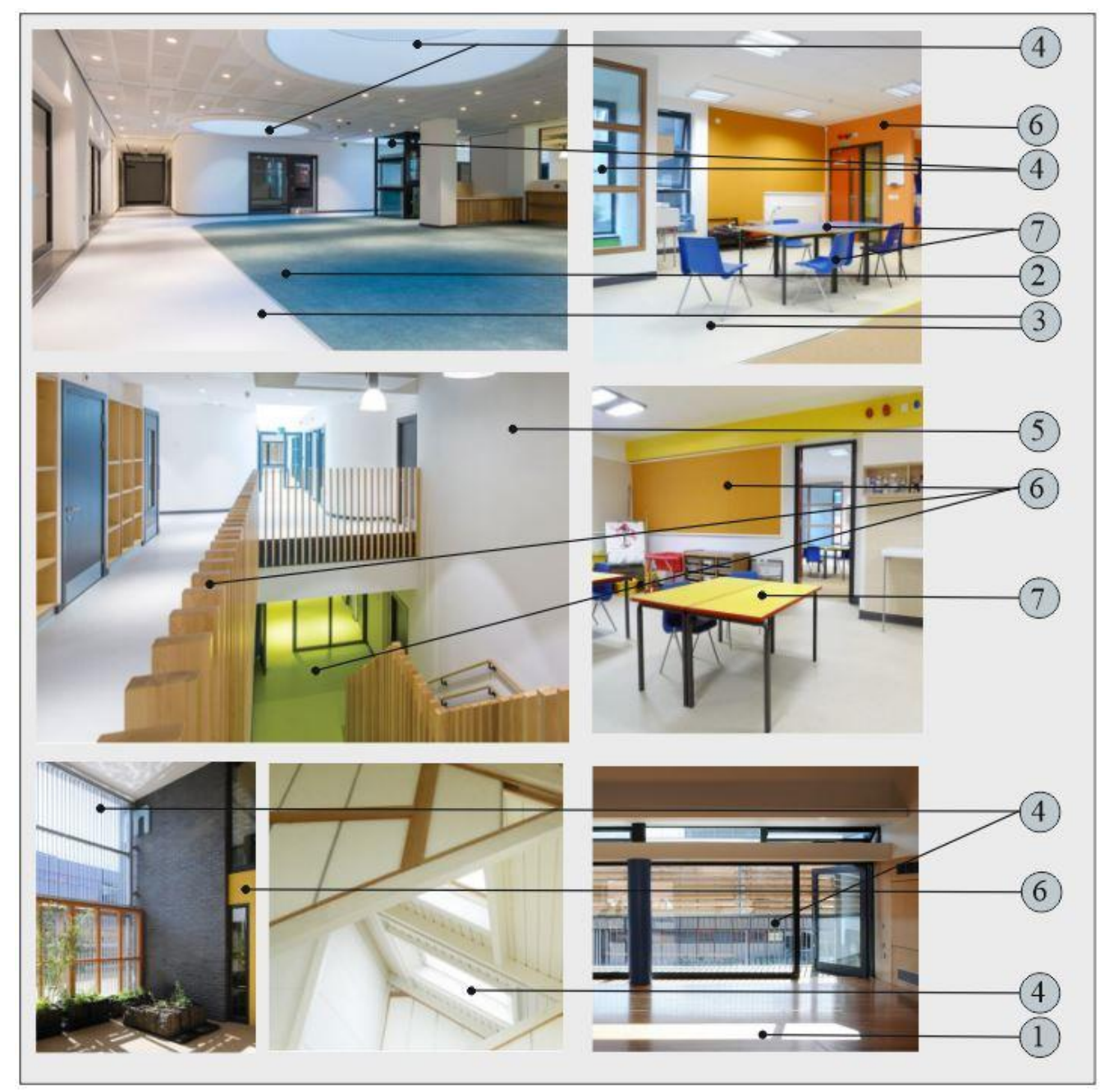

Fig. 4. Design of Frank Barnes School (URL: https://www.aabarchitects.co.uk/frank-barnes/)

The next criterion is mobility and accessibility, which contribute to visual transparency and intuitive navigation, related to the solution of issues of convenient communication in the process of moving with the ability to move freely in the architectural space and at the same time see your interlocutor. The design-organization of the educational space, in this case, should be decided by the open type of planning decision and take into account important tasks, namely: 1) the presence of extended stairs; 2) the presence of wide automatic doors, preferably with transparent glass inserts; 3 ) the presence of slopes and ascents with a small angle of inclination (for free movement of students and their simultaneous communication); 4) rounded turns and shapes of architectural structures (to avoid collisions with other people); 5) combinatorial design organization of furniture in space - on the basis of radial forms (to create a circle of communication and support communication, common for people with hearing impairments) and with the possibility of 
reorganization in the process of communication; 6) marking on vertical surfaces (walls, enclosing structures).

The analysis of theoretical and visual material showed that the importance of developing an inclusive learning space that takes into account the adaptation of children with special needs today is significantly accelerated. Thus, the chief designer of the famous project Universal Design for Learning (UDL) - Brian Dean, believes that the design of modern learning spaces should suit all children without exception ${ }^{2}$. The designer reveals the content of the Universal Design for Learning (UDL) project, emphasizing that this work provides many opportunities for educating children, identifying their self-efficacy and means of self-improvement. In addition, Brian Dean reveals the main components for solving the design of the learning space based on the principles of universal design, namely:

- design organization of a flexible learning space that promotes students' creativity, their critical thinking, group cooperation, communication and communication;

- development of safe premises, where you can study both in groups and individually;

- availability of subject-spatial environment, which provides many ways of self-regulation and self-discovery of a child with special needs and a regular student;

- free space and development of planning decisions that meet the specific needs of the student;

- development of several variants of acoustics, variants of the child's movement;

- offer to equip the room with light furniture with a soft surface and the ability to change the height of the tables - to allow students to move, stand, sit and swing;

- offer several ways to present information: visual, tactile, sensory - for auditory, visual and kinesthetic processing of information by a child ${ }^{3}$.

An example in fig. 5 confirms the implementation of the criteria of mobility and accessibility in the formation of the educational space. The design of the classroom, developed on the basis of the principle of flexibility, clearly proves the possibility of creating modern school interiors that take into account: color, combinatorial possibilities of planning, the use of natural light, acoustics, environmentally friendly finishing materials and more. It should be emphasized that by using radial shapes of furniture and rounded corners in interior design, designers make the room mobile and flexible, as students have

\footnotetext{
${ }^{2}$ Classroom design is the next frontier in universal design. URL: https://www.elledecor.com/lifeculture/a29547925/classroom-universal design-for-learning/.

${ }^{3}$ Classroom design is the next frontier in universal design. URL: https://www.elledecor.com/lifeculture/a29547925/classroom-universal design-for-learning/.
} 
the opportunity to communicate and be safe. Researchers Robert Sirvage \& Rebecca Sheir in their research also focus on this aspect ${ }^{4}$ :

- absence of superfluous architectural designs on which it is not visible use of sound-absorbing materials, taking into account the features of acoustics;

- choice of materials that do not have a glossy surface;

- maximum daylight (presence of large windows, top natural light);

- the presence of chairs that tilt in different directions;

- creation of new configurations of workplaces by means of combinatorics.

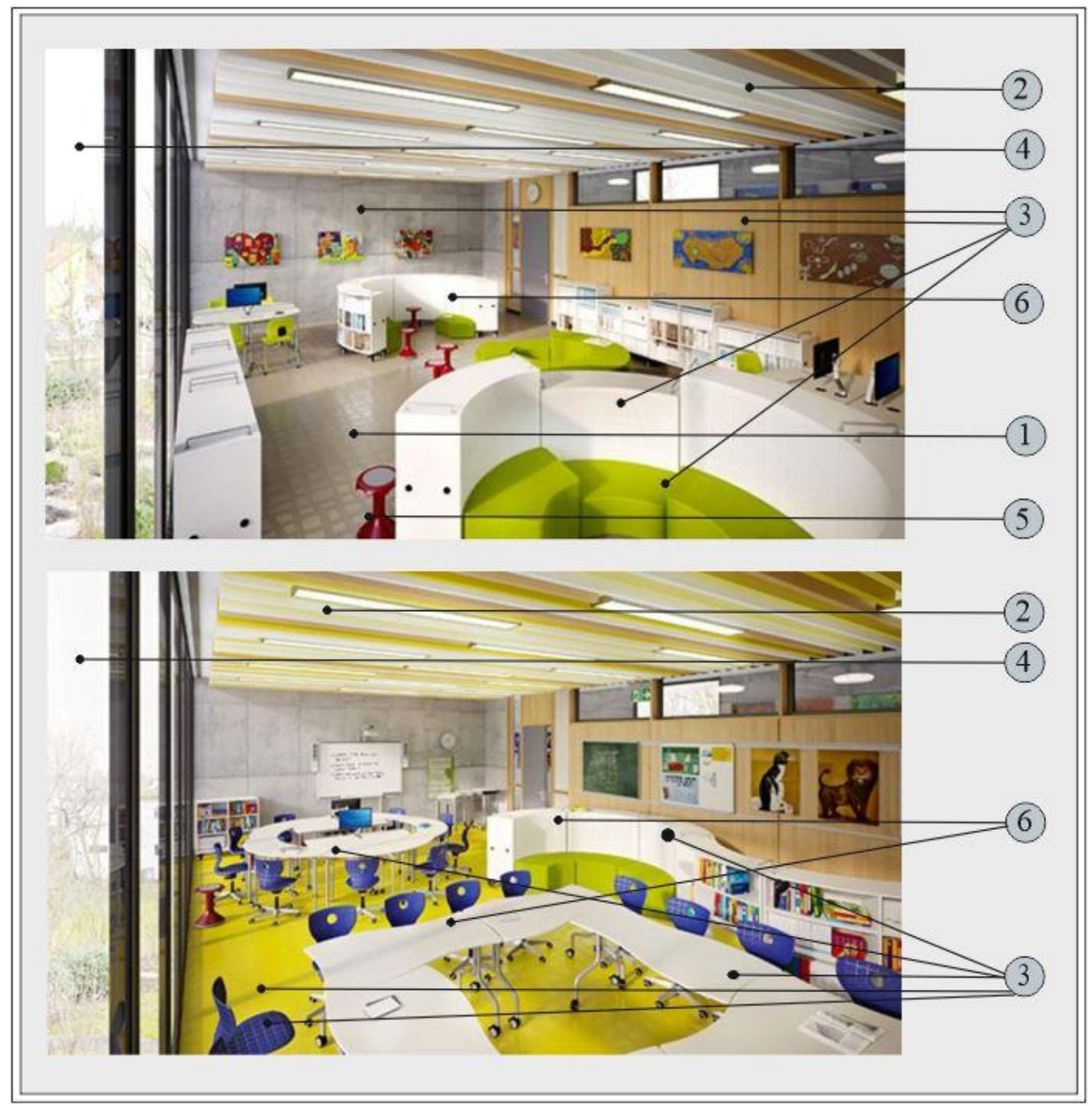

Fig. 5. Design of the educational space of a modern school, created on the basis of the principle of flexibility (URL: https://www.connectingelements.com/our-blog/classroom-design-how-topositively-impact-student-learning-with-design.aspx\#.V0Ta2JErLIV)

\footnotetext{
4 Classroom design is the next frontier in universal design. URL: https://www.elledecor.com/lifeculture/a29547925/classroom-universal design-for-learning/.
} 
Determining the next criterion, which is related to solving the problems of color-tonal relationships in creating a classroom design for children with hearing impairments, is very important. According to research, matte surfaces of blue and green shades are desirable. Analysis of the material showed that they harmoniously contrast with the shades of human skin. In the process of perception of such an interior by the interlocutors, each of them receives positive emotions. In addition, the result of this design decision is a comfortable perception of the gesturing interlocutor, whose skin color is manifested against the background of the proposed color scheme in the room.

No less important criterion is to take into account the characteristics of light. The natural task in improving the quality of the design of the educational space in which children with hearing impairments study is to make maximum use of a large amount of natural light. Artificial lighting is proposed to be soft, diffused, without excessive illumination and brightness, preferably without differences in illumination. No less important, in this case, is the combination of utilitarian function with aesthetic. Example fig. 4, 5 confirms the abovementioned. The criterion related to the solution of problems of effective acoustics needs special attention. Acoustics is one of the main factors that need to be addressed in the design organization of a modern secondary school. Where students with hearing impairments study, the architectural space of the secondary school should be free of distracting and annoying sounds. To date, significant results in creating an effective acoustic environment for school premises have been obtained by the Central Institute for the Deaf (CID). Studies conducted by leading architects and acoustic engineers have shown that the noise level between classrooms should be more than $50 \mathrm{~dB}$, reverberation time $-0.4 \mathrm{~s}$. Where students rest noisily (corridor space and group space), researchers have proposed higher noise levels and longer reverberation times. This approach gives hearing-impaired children the opportunity to adapt to a future independent life, where there is unnecessary noise and sharp sounds.

It should be noted that background noise or the presence of reverberation in school interiors is an uncontrolled process and distracts all students from the learning process without exception. However, for children with hearing impairments, solving the problems of poor quality acoustics is almost a priority. Echoes of sounds occur when they are reflected from hard surfaces in the classroom: from the surfaces of walls, windows, ceilings, floors and desks. Prolonged reverberation also reduces the effectiveness of language perception of participants in the learning process. The result of the negative effects of acoustics are: 1) poor reading skills; 2) misunderstanding of language quality; 3) deterioration of student behavior in the classroom; 4) decreased attention; 5) reducing the quality of academic performance. It is worth noting that the consequences of poor acoustics also have a negative impact on teachers' 
health. When raising the voice during communication, which is almost $60 \%$ of their working time, teachers have problems with the voice. The above requires the disclosure of the main provisions that can be used in the design organization of the training space to improve the quality of acoustics, namely:

- use of acoustic panels (as enclosing structures, ceiling elements, decorative panels or wall cladding);

- use of wooden rails on the ceiling that scatter sound waves;

- use of a double wall to insulate the classroom;

- use of acoustic insulating glass;

- use of carpets with short pile on the floor;

- decorating the walls with creative works of students;

- keeping a small angle at the surfaces of the student's desk - to reduce the level of sound echo;

- conducting classes with closed doors and windows.

Consider the main types of acoustic panels and compositional techniques for their use in shaping the design of secondary schools (fig. 6).

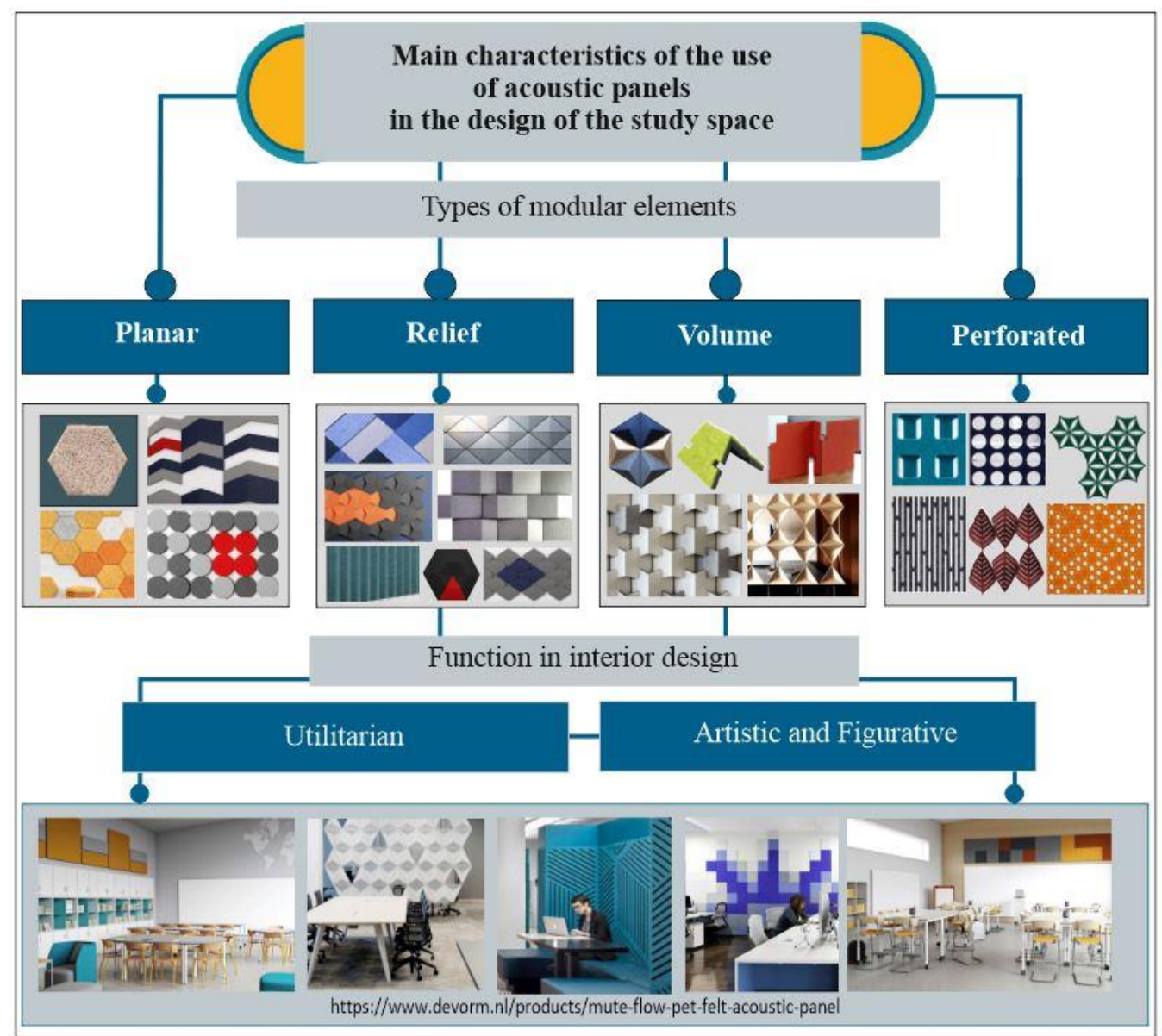

Fig. 6. Main characteristics of the use of acoustic panels in the design of the study space 
Basic criteria: 1) functionality; 2) compliance with the criteria of modern fashion and stylistic trends; 3) rationality and purposefulness; 4) ergonomics; 5) economy; 6) use of secondary raw materials; 7) variety of technological processes; 8) ease of installation and operation; 9) color variability; 10) compliance with the requirements of the universal design.

Compositional techniques:

- conceptual combinatorics: the idea of constructing modular variability combinations based on geometric, constructive, color characteristics;

- formal combinatorics: 1) asymmetry - symmetry (mirror, figurative, similarity symmetry, rhombic, hair, parallelogram); 2) reception of the report composition; 3) statics - dynamics; 4) receiving a combination of external and the inner surface of the module; 5) reception of contrast (nuance) of color.

The analysis of the material showed that in the conditions of constant improvement of technologies and materials, their range has significantly expanded. The following types can be referred to sound-absorbing systems: 1) acoustic sound-absorbing systems for walls; 2) suspended sound-absorbing acoustic ceilings; 3) multifunctional sound-absorbing partitions. In addition, the modern market of acoustic materials offers sound-absorbing systems to address the design of the training space, including: 1) panels of fine wood fiber; 2) panels using foam; 3) polyolefin fabric; 4) perforated gypsum boards; 5) panels of wood chips, cement; 6) plates from polyurethane foam; 7) wool panels; 8) acoustic wallpaper; 9) high-density fiberglass panels; 10) panels of pressed felt. All materials effectively solve the problem of unnecessary noise and echoes in the premises of the secondary school. In addition, it should be noted that speakers are valuable from a design point of view, as they form aesthetically pleasing compositions, due to the shape of the modules and various textures. It is worth noting that an integral part of the design of speakers is the concept of the author. It reveals the main idea in creating the features of the future element of the panels (its shape, color, size). For example, the discovery of designer Sas Adrienssens, who offered acoustic wallpaper BuzziSkin. Among the main characteristics of acoustic wallpaper are the following:

- texture density of pressed wool;

- a large number of colors in the collection;

- sound improvement;

- reduction of unnecessary noise.

In addition, the scattering of energy of acoustic oscillations in the room has several reasons: first, due to the viscosity of the air, which contains quite a lot of oscillations in the internal volume of the room; secondly, there is friction of residual energy on the surface, which also have a significant total area. Thus, the use of acoustic materials significantly improves the acoustic characteristics in the design of the school space. 


\section{CONCLUSIONS}

The study revealed the importance of a human-centered approach to solving the problems of students with hearing impairments. The main criteria of the DeafSpace Design concept are systematized, which is promising in the formation of the design of the subject-spatial environment of secondary schools in the context of globalization. The principles and methods of implementing the idea of the concept of DeafSpace Design are revealed, which is confirmed by meaningful design developments of designers and architects. Visual material of project proposals is provided with the definition of the main aspects of the implementation of the DeafSpace Design concept in the interiors of secondary schools.

\section{SUMMARY}

The research materials present the results of determining the main criteria of the DeafSpace Design concept, with the help of which leading architects and designers solve the problems of students with hearing impairments in the educational space of secondary school. The historical terms of the concept development, its philosophy and the state of the design organization in the present conditions are determined. The importance of a human-centered approach to solving the problems of students with hearing impairments who study together with ordinary children is revealed. The main principles of forming a creative learning environment are analyzed. The basic methods of forming the design of the planning solution of the classroom space with the provision of visual and acoustic equivalence for students with hearing impairments are established. The generalized tables and figures provide a systematization of techniques for creating a general composition of school premises, based on the arrangement of architectural elements and decor elements, balanced color and tonal relationships and successful compositional solution of workplaces based on the reception of mirror symmetry. The given examples of the best examples of design of educational space of comprehensive schools reflect the modern inclusive approach to processes of aesthetic education of pupils.

\section{REFERENCES}

1. Bauman H. Deaf Diverse Design Guide. Identifying the Principles of Deaf Space. 2008, November 9. URL: http://www.dangermondarchitects.com/blog/.

2. Бондаренко В., Кривуц С. Питання екології в системі міського середовища. ADVANCES OF SCIENCE : proceedings of articles the international scientific conference. Czech Repablic, Karlovy Vary ; Ukraine, Kyiv : MCNIP, 2018. P. 72-73.

3. Byrd T. Deaf Space. Gallaudet Today: The Magazine. Spring 2007. 
4. Visual attention to the periphery is enhanced in congenitally deaf individuals / D. Bavelier et al. Journal of neuroscience. Society for Neuroscience. 2000. Vol. 20. Is. 17. P. 92-94.

5. Organization of Pedagogical Relationships between Learners and Teachers in the Framework of Inclusive Education / O. Gonchar et al. Românească pentru Educaţie Multidimensională. 2019. № 11 (2). P. 126-140. DOI: $10.18662 / \mathrm{rrem} / 121$.

6. Johnson Ch. Articulation of Deaf and Hearing Spaces Using Deaf Space Design Guidelines: A Community Based Participatory Research with the Albuquerque Sign Language Academy. 2010. URL: https:// digitalrepository.unm.edu/arch_etds/1.

7. Classroom design is the next frontier in universal design. URL: https://www.elledecor.com/life-culture/a29547925/classroom-universal designfor-learning/.

8. Wauters L., Knoors H. Social Integration of Deaf Children in Inclusive Settings. Journal of Deaf Studies and Deaf Education. 2007. № 13 (1). P. 21-36. DOI: 10.1093/Deaf ed/enm028.

9. National Dissemination Center for Children with Disabilities. NICHCY : Information Portal. 2012. URL: http://nichcy.org/laws.

10. Nikolaraizi M. The Role of Educational Experiences in the Development of Deaf Identity. Journal of Deaf Studies and Deaf Education. 2006. Vol. 11 (4). P. 477-492. DOI: 10.1093/Deafed/enl003.

11. Sirvage Robert, Sheir Rebecca. HBBM Architecture. 2008.

Information about author:

Katrichenko K. O.,

Graduate Student at the Department of Design Environment

Kharkiv State Academy of Design and Arts

8, Mystectv str., Kharkiv, 61002, Ukraine 